\title{
STUDENT LEARNING PREFERENCE: THE IMPACT OF HORIZONTAL ALIGNMENT COMPARING SECOND AND THIRD YEAR COHORTS UNDERTAKING A PHARMACEUTICAL ANALYSIS COURSE IN THE SCHOOL OF PHARMACY, GRIFFITH UNIVERSITY, AUSTRALIA
}

\author{
Abdullah Karaksha ${ }^{1,3}$, Andrew K. Davey ${ }^{2,3}$, Andrew R. Battle ${ }^{2,3}$ \\ ${ }^{1}$ School of Medical Science, Griffith University, Gold Coast Campus (AUSTRALIA) \\ ${ }^{2}$ School of Pharmacy, Griffith University, Gold Coast Campus (AUSTRALIA) \\ ${ }^{3}$ Menzies Health Institute, Gold Coast Campus, Southport (AUSTRALIA)
}

\begin{abstract}
Background: The current teaching and learning approach in student education adopted by higher education institutions is through transformation of the students' learning experience to encourage deep approaches, enabling them to attain more sophisticated beliefs about learning and knowledge. This era is very exciting but also challenging as universities have been subject to increasing demands for quality in teaching and learning. Pharmacy schools around Australia are no exception with constant demands from accreditors to better prepare the students for the workforce. The 3rd year Pharmaceutical Analysis course introduces students to a range of pharmaceutical analysis and spectroscopic techniques important to the hospital, community, and industrial pharmacy settings. Students found this course challenging and it was deemed more appropriate to be offered during second year to better horizontally align with other courses offered in the school. We therefore set out to analyse and compare student preferences between 2nd and 3rd year cohorts when they were offered the same course at the same time.
\end{abstract}

Method: This study was conducted at the School of Pharmacy, Griffith University, Gold Coast Campus, Southport, Australia. Ethical approval was granted by the Griffith University Human Ethics Committee (PHM14/13/HREC).

Pharmaceutical Analysis is a semester (13 week) long 3rd year course (3026PHM). In 2013 the course was offered for the first time for 2 nd year students, the course code being changed to 2008PHM. Therefore, for the academic year 2013, the course was delivered concurrently to $2 \mathrm{nd}$ and 3 rd year students. Both cohorts sat in the same lectures, tutorials and laboratories and undertook the same assessment items.

Student preference was measured in terms of the student evaluation of course (SEC) and student evaluation of teaching (SET). Both surveys offered the students the chance to rate and comment on the course quality and teaching team anonymously. These surveys are based on the five-point Likert scale (Strongly disagree, disagree, neutral, agree, strongly agree) and include six and five questions respectively.

Results: A total of 90 and 67 students enrolled in 3026PHM and 2008PHM respectively in the academic year 2013. Overall 32 student (36\%) from 3026PHM and 28 students (42\%) from 2008PHM responded to the surveys. There were statistically significant differences in almost all questions with students from 2008PHM showing more positive responses. In particular, 2nd year students were more positive than 3rd year students in terms of engagement with the course $(3.5 \pm 1.04$ vs $2.6 \pm 1.11, p<$ $0.05)$, reporting that the course was effective in their learning $(3.9 \pm 0.9$ vs $2.8 \pm 1.18, p<0.05)$ and in overall satisfaction with the quality of the course $(3.9 \pm 0.85$ vs $2.7 \pm 1.18, p<0.05)$.

Conclusion: Pharmacy students are generally positive about laboratory-based courses but these tend to be run in the early stages of the program with experiential placements preferred by students in the later stages of the program. In this example, the evidence clearly showed that there was a misalignment between Pharmaceutical Analyses and other courses in the program. A simple strategy of moving the course to ensure better horizontal alignment at the second year level appears to have resulted in a significant improvement in student engagement and satisfaction.

Keywords: Pharmaceutical analysis, pharmacy education, constructive alignment. 


\section{INTRODUCTION}

The current teaching and learning approach adopted by higher education institutions is to encourage transformation of the students' learning experience to encourage deep approaches to learning, enabling them to attain more sophisticated beliefs about learning and knowledge. This era is very exciting but also challenging as universities have been subject to increasing demands for quality in teaching and learning (Biggs 2001). Pharmacy schools around Australia are no exception with constant demands from accreditors to better prepare the students for the workforce (APC 2002).

From the students' perspective, however, things are seen differently. Students often approach courses, tasks and exams strategically to achieve the highest mark while applying the least effort possible (Scouller 1998). Biggs identified two approaches to learning: surface and deep approaches. Students utilising the surface approach usually apply rote learning and memorisation techniques to study. On the other hand, a deep learning approach encourages students to make connections between and understand concepts (Biggs 2011). Using this approach, students can successfully apply their knowledge to different settings and scenarios. Interestingly, students can be both surface learners in certain tasks (when the weighting of the task is small for instance) and deep learners for other assessment pieces as required (Biggs 2001). The role of academics is becoming more important to encourage their students to apply deep approaches more often. This is particularly important because the adoption of deep learning strategies is expected to improve the learning experience and academic performance, and that surface learning strategies are likely to be counterproductive to achieving these outcomes (Elliot and Church 1997).

It is hypothesized, in the higher education sector, that students learning methods will mature as they progress through their degrees, with the result that more productive approaches to learning will increase at the expense of less productive ones (Trigwell and Prosser 1991). In other words, with increasing experience and age, and upon exposure to facilitating teaching and assessment practices, students are expected to employ deeper learning strategies and become independent learners, with decreased reliance on external help. It is further hypothesized that adoption of these productive approaches will also be reflected in student academic performance (Smith 2007). Students can be encouraged and directed to progress to deep learning strategies using the constructive alignment theory. Biggs suggested that any course should have constructive alignment in its structure, so as the course objectives are aligned with the content which is also aligned with the assessment tasks and learning objectives of the course (Biggs 1996).

Relating to deep and surface approaches to learning, we have identified the Pharmaceutical Analysis course, offered at the School of Pharmacy, Griffith University, Australia as a course of concern. This course introduces students to a range of pharmaceutical analysis techniques important to the hospital, community, and industrial pharmacy settings. The lecture component provides the theory component while the laboratory aspect of the course provides an opportunity for students to apply theoretical concepts in a "hands on" experimental context. Students entering the Pharmaceutical Analysis course have varying backgrounds and levels of confidence in the basic sciences, ranging from entry-level science courses (general and organic chemistry) to full degrees (usually in chemistry or biochemistry). The vast majority of these students have not been exposed to pharmaceutical analysis and this has limited their understanding (and application) of the science and research involved (Albon and Hubball 2004). Typically, students struggle with this section of the course. First-time exposure to this topic along with a lack of alternate learning activities to help students integrate the theory and application exacerbates the issue. In other areas of the pharmaceutical analysis course, active-learning strategies such as case studies and "hands-on" laboratory exercises have become particularly important for student learning (Albon and Hubball 2004, Albon, Cancilla et al. 2006). Moreover, pharmacy students are generally positive about laboratory-based courses but these tend to be run in the early part of the program with experiential placements preferred by students in the later stages of the program (Davey, Grant et al. 2013). The placement of the course within the curriculum was of particular concern. There was no clear relationship between Pharmaceutical Analysis and other third year courses in the same semester. However, in $2^{\text {nd }}$ year the students were beginning to study the principles of Pharmaceutics where issues such as dissolution and quality control could be linked to the need for pharmaceutical analysis, Pharmacokinetics, and Drug Discovery and Development where, for example, discussion of the need for accurate analysis of drug in blood samples occurs. To address the above issues and to improve the student experience, it was deemed more appropriate to offer the course during second year to better horizontally align with other courses offered at that year level. We therefore set out to analyse and compare student preferences between second and third year cohorts when they were offered the same course at the same time. 


\section{METHODOLOGY}

This study was conducted at the School of Pharmacy, Griffith University, Gold Coast Campus, Australia. Ethical approval was granted by the Griffith University Human Ethics Committee (PHM14/13/HREC). Pharmaceutical Analysis is a semester (13 week) long 3rd year course (3026PHM) normally delivered by means of three hours of didactic teaching per week. Weekly tutorials and laboratories total 2 to 4 hours. In 2013 the course was offered for the first time to 2nd year students, the course code being changed to 2008PHM. Therefore, for the academic year 2013, the course was delivered concurrently to 2 nd and 3rd year students. Both cohorts sat in the same lectures, tutorials and laboratories and undertook the same assessment items.

Student satisfaction was obtained from the student evaluation of course (SEC) reports which detailed their preference and attitude towards the pharmaceutical analyses course with quantitative questions graded according to a 5-point Likert Scale (Strongly disagree, disagree, neutral, agree, strongly agree). The quantitative questions asked students whether the course was organised, whether it was engaging, whether the teaching was effective, whether assessment was clear/fair with appropriate feedback, and lastly whether students were satisfied overall. Secondly, student evaluation of teaching (SET) was also considered to obtain student preference towards the teaching team. The quantitative questions asked students whether the staff member presented material in a clearly organised and interesting way, whether the academic treated students with respect, showed good knowledge in the topic and finally how well they were satisfied with the teaching quality of the academic. Participation in those surveys is voluntary and all responses are recorded anonymously. The surveys usually open at the last week of teaching semester and they remain accessible for two weeks.

Student performance was also compared as measured by overall course grade (measured quantitatively as a percentage. Course grade was also categorised into grade levels, with $\geq 85 \%$ classified as 'High distinction', $\geq 75-84 \%$ classified as 'Distinction', with $\geq 65-74 \%$ classified as 'Credit', $\geq 50-64 \%$ classified as 'Pass', and $<50 \%$ classified as a 'Fail'. The average of the final grade was compared between the 2 nd and 3rd year students.

Finally, student attitudes towards the course 2008PHM was evaluated and compared across the three academic years 2013, 2014 and 2015 using the SEC and SET reports.

\subsection{Data analysis}

Gender was compared between the two academic cohorts using chi-square. Grade point average (GPA), student responses to the SEC and SET reports, and students final grades were compared between the students from the 2008PHM and 3026PHM cohorts using independent samples t-tests. Moreover, ANOVA was used to detect any statistical significant differences in student responses to the SEC and SET reports for the course 2008PHM between the three academic years $(2013,2014$, 2015). These statistical analysis tests were performed using GraphPad InStat 3. Probability (P) values of less than 0.05 were considered statistically significant.

\section{RESULTS}

A total of 90 and 67 students enrolled in 3026PHM and 2008PHM respectively in the academic year 2013. There was no statistical significant difference between the two groups in terms of gender, (figure $1 ; \mathrm{P}>0.05)$. 


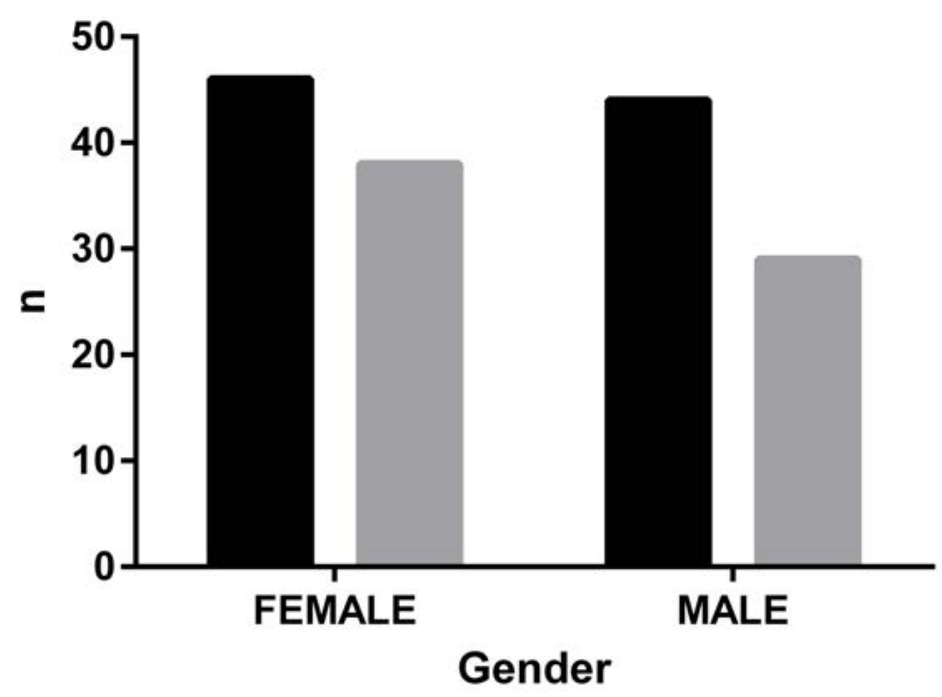

\section{PHM \\ 2008PHM}

Figure 1: gender comparison between $2^{\text {nd }}$ and $3^{\text {rd }}$ year students.

Students from $3^{\text {rd }}$ year had an average GPA of $(5.19 \pm 0.90)$, while $2^{\text {nd }}$ year students achieved an average GPA of $(4.88 \pm 0.96)$. The difference was statically significant, $(t=2.07, p=0.04)$, figure 2 .

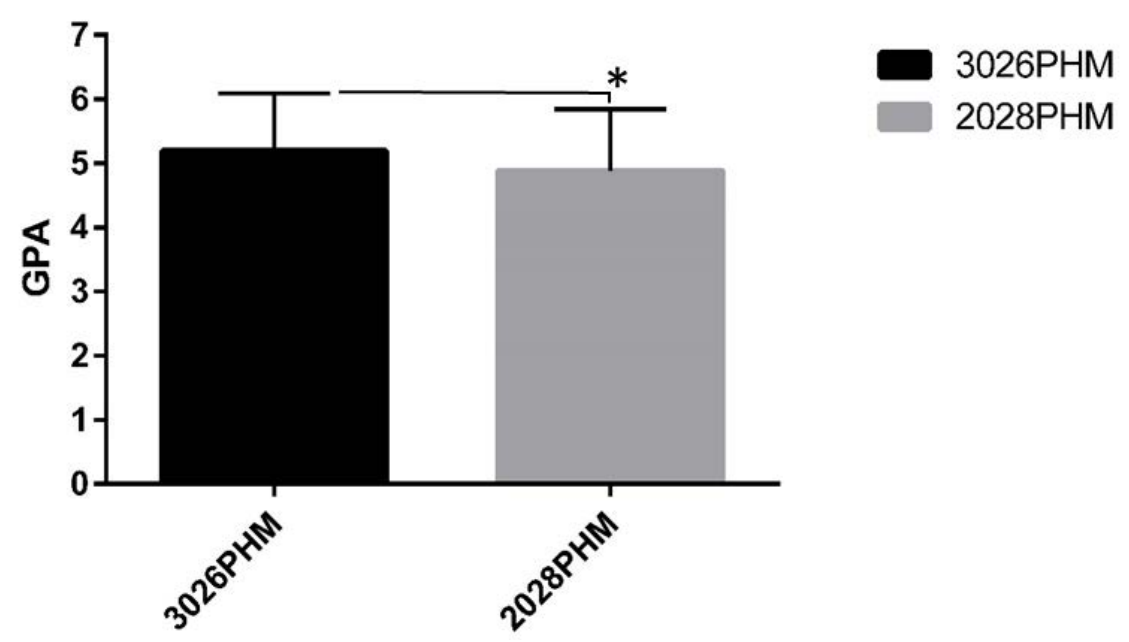

Figure 2: student GPA comparison between $2^{\text {nd }}$ and $3^{\text {rd }}$ year students.

Overall 32 students $(36 \%)$ from $3026 \mathrm{PHM}$ and 28 students (42\%) from 2008PHM responded to the surveys. There were statistical significant differences in all questions with students from 2008PHM showing more positive responses. In particular, 2nd year students were more positive than 3rd year students in terms of engagement with the course $(3.5 \pm 1.04$ vs $2.6 \pm 1.11, p<0.05)$, reporting that the course was effective in their learning $(3.9 \pm 0.9$ vs $2.8 \pm 1.18, p<0.05)$ and in overall satisfaction with the quality of the course $(3.9 \pm 0.85$ vs $2.7 \pm 1.18, p<0.05)$ (table 1$)$.

Table 1: SEC results comparison between 2008PHM and 3026PHM for the academic year 2013:

\begin{tabular}{lccc}
\hline Variable & $\begin{array}{c}\text { 2008PHM } \\
\text { Mean } \pm \text { SD }\end{array}$ & $\begin{array}{c}\text { 3026PHM } \\
\text { Mean } \pm \text { SD }\end{array}$ & Statistic, $p$ value \\
\hline This course was well-organised & $3.9 \pm 0.71$ & $2.9 \pm 1.16$ & $t=3.96, p=0.0002^{*}$ \\
\hline The assessment was clear and fair & $4.0 \pm 0.58$ & $2.9 \pm 1.01$ & $t=5.07, p=0.0001^{*}$ \\
\hline $\begin{array}{l}\text { I received helpful feedback on } \\
\text { assessment work }\end{array}$ & $3.6 \pm 0.92$ & $2.8 \pm 1.10$ & $\mathrm{t}=3.03, \mathrm{p}=0.004^{*}$ \\
\hline This course engaged me in learning & $3.5 \pm 1.04$ & $2.6 \pm 1.11$ & $\mathrm{t}=3.23, \mathrm{p}=0.002^{*}$ \\
\hline
\end{tabular}


The teaching (lecturers, tutors, online etc) on this course was effective in helping me

$3.9 \pm 0.9$

$2.8 \pm 1.18$

$t=4.01, p=0.0002^{*}$ to learn

\begin{tabular}{|c|c|c|c|}
\hline $\begin{array}{l}\text { Overall I am satisfied with the quality of this } \\
\text { course }\end{array}$ & $3.9 \pm 0.85$ & $2.7 \pm 1.18$ & $t=4.46, p=0.0001^{*}$ \\
\hline
\end{tabular}

The same number of students also completed the SET report. Again, students from 2008PHM showed more positive responses than students from 3026PHM. Interestingly, there was no significant difference between the two groups in only one question related to the way the academic staff member treated the students $(4.5 \pm 0.69$ vs $4.2 \pm 0.93, p>0.05)$.

Table 2: SET results comparison between 2008PHM and 3026PHM for the academic year 2013:

\begin{tabular}{lccc}
\hline Variable & $\begin{array}{c}\text { 2008PHM } \\
\text { Mean } \pm \text { SD }\end{array}$ & $\begin{array}{c}\text { 3026PHM } \\
\text { Mean } \pm \text { SD }\end{array}$ & Statistic, $p$ value \\
\hline $\begin{array}{l}\text { This staff member presented material in a } \\
\text { clearly organised way }\end{array}$ & $3.9 \pm 0.69$ & $2.7 \pm 1.14$ & $\mathrm{t}=4.85, \mathrm{p}=0.0001^{*}$ \\
\hline $\begin{array}{l}\text { This staff member presented material in an } \\
\text { interesting way }\end{array}$ & $3.6 \pm 0.99$ & $2.6 \pm 1.08$ & $\mathrm{t}=3.72, \mathrm{p}=0.0005^{*}$ \\
\hline $\begin{array}{l}\text { This staff member treated students with } \\
\text { respect }\end{array}$ & $4.5 \pm 0.69$ & $4.2 \pm 0.93$ & $\mathrm{t}=1.40, \mathrm{p}=0.17$ \\
\hline $\begin{array}{l}\text { This staff member showed a good } \\
\text { knowledge of the subject matter }\end{array}$ & $4.3 \pm 0.71$ & $3.4 \pm 1.36$ & $\mathrm{t}=3.15, \mathrm{p}=0.003^{*}$ \\
\hline $\begin{array}{l}\text { Overall I am satisfied with the teaching of } \\
\text { this staff member }\end{array}$ & & & \\
\hline
\end{tabular}

Student performance in the course was measured on the following scale: $3=$ fail, $4=$ pass, $5=$ credit, $6=$ distinction, $7=$ high distinction. Third year students had an average grade of $(5.3 \pm 0.91)$ which was higher than their peers from the second year cohort who obtained an average of $(4.9 \pm 0.93)$. The difference is statistically significant $(t=2.44, p=0.016)$.

Student evaluation of the 2008PHM course for the academic years 2013, 2014 and 2015 showed no statistical significant difference in any of the questions $(p>0.05)$, table 4 .

Table 3: SEC results comparison for the course 2008PHM in the academic years 2013, 2014 and 2015.

\begin{tabular}{lcccc}
\hline Variable & $\begin{array}{c}2013 \\
\text { Mean } \pm \text { SD }\end{array}$ & $\begin{array}{c}2014 \\
\text { Mean } \pm \text { SD }\end{array}$ & $\begin{array}{c}\text { 2015 } \\
\text { Mean } \pm \text { SD }\end{array}$ & Statistic, $p$ value \\
\hline This course was well-organised & $3.9 \pm 0.71$ & $3.3 \pm 1.10$ & $3.9 \pm 0.78$ & $\mathrm{~F}=2.24, \mathrm{p}=0.11$ \\
\hline The assessment was clear and fair & $4.0 \pm 0.58$ & $3.5 \pm 1.2$ & $4.1 \pm 0.60$ & $\mathrm{~F}=2.06, \mathrm{p}=0.14$ \\
\hline $\begin{array}{l}\text { I received helpful feedback on my } \\
\text { assessment work }\end{array}$ & $3.6 \pm 0.92$ & $3.5 \pm 1.04$ & $4.0 \pm 1.0$ & $\mathrm{~F}=0.77, \mathrm{p}=0.47$ \\
\hline $\begin{array}{l}\text { This course engaged me in learning } \\
\text { The teaching (lecturers, tutors, }\end{array}$ & $3.5 \pm 1.04$ & $3.0 \pm 1.26$ & $3.8 \pm 0.97$ & $\mathrm{~F}=1.45, \mathrm{p}=0.24$ \\
\hline $\begin{array}{l}\text { online etc) on this course was } \\
\text { effective in helping me to learn }\end{array}$ & & $3.2 \pm 1.38$ & $4.2 \pm 0.67$ & $\mathrm{~F}=2.87, \mathrm{p}=0.07$ \\
\hline $\begin{array}{l}\text { Overall I am satisfied with the } \\
\text { quality of this course }\end{array}$ & $3.9 \pm 0.85$ & $3.3 \pm 1.27$ & $3.8 \pm 0.97$ & $\mathrm{~F}=1.5, \mathrm{p}=0.23$ \\
\hline
\end{tabular}

Similarly, student evaluation of the teaching for the course 2008PHM across the three academic years (2013 - 2015) showed no statistical significant difference in any of the questions, table 5. 
Table 4: SET results comparison for the course 2008PHM in the academic years 2013, 2014 and 2015.

\begin{tabular}{lcccc}
\hline Variable & $\begin{array}{c}2013 \\
\text { Mean } \pm \text { SD }\end{array}$ & $\begin{array}{c}2014 \\
\text { Mean } \pm \text { SD }\end{array}$ & $\begin{array}{c}2015 \\
\text { Mean } \pm \text { SD }\end{array}$ & Statistic, $p$ value \\
\hline $\begin{array}{l}\text { This staff member presented } \\
\text { material in a clearly organised way }\end{array}$ & $3.9 \pm 0.69$ & $3.2 \pm 1.22$ & $4.0 \pm 0.87$ & $\mathrm{~F}=3.01, \mathrm{p}=0.06$ \\
\hline $\begin{array}{l}\text { This staff member presented } \\
\text { material in an interesting way }\end{array}$ & $3.6 \pm 0.99$ & $3.3 \pm 1.19$ & $3.9 \pm 0.93$ & $\mathrm{~F}=0.85, \mathrm{p}=0.43$ \\
\hline $\begin{array}{l}\text { This staff member treated students } \\
\text { with respect }\end{array}$ & $4.5 \pm 0.69$ & $4.3 \pm 0.65$ & $4.6 \pm 0.88$ & $\mathrm{~F}=0.48, \mathrm{p}=0.62$ \\
\hline $\begin{array}{l}\text { This staff member showed a good } \\
\text { knowledge of the subject matter }\end{array}$ & $4.3 \pm 0.71$ & $3.8 \pm 0.90$ & $4.6 \pm 0.88$ & $\mathrm{~F}=2.74, \mathrm{p}=0.08$ \\
\hline $\begin{array}{l}\text { Overall I am satisfied with the } \\
\text { teaching of this staff member }\end{array}$ & $4.0 \pm 0.74$ & $3.4 \pm 1.29$ & $4.1 \pm 0.93$ & $\mathrm{~F}=1.98, \mathrm{p}=0.15$ \\
\hline
\end{tabular}

\section{DISCUSSION}

The aim of this study was to analyse and compare student preferences between 2nd and 3rd year cohorts when they sat the same pharmaceutical analysis course concurrently. The data showed no significant difference in terms of gender between the two cohorts.

Students from the $3^{\text {rd }}$ year cohort achieved significantly better grades in the course than $2^{\text {nd }}$ year students. This is an expected outcome as students' progress into their degrees they become more independent and apply deeper learning approaches (Trigwell and Prosser 1991). Students from $3^{\text {rd }}$ year therefore have more experience in undertaking assessments and exams and this was reflected in their academic standing in this course. Moreover, $3^{\text {rd }}$ year students had significantly higher GPA than their peers from the $2^{\text {nd }}$ year $(5.3 \pm 0.81$ vs $4.88 \pm 0.96, p<0.05)$. GPA is a strong indicator of academic performance and is positively correlated to performance (Willey, Edwards et al. 2011, Sonnert and Fox 2012). This might have also contributed to the fact that $3^{\text {rd }}$ students achieved better grade in the course, however it should be noted that if the student is following the normal pathway through the degree they would have undertaken more courses by third than second year and so it is difficult to obtain a direct comparison.

However, looking at the SEC and SET reports revealed a major problem in the course offering (tables $1 \& 2$ ). Student feedback obtained through SEC and SET has been considered as the only indicator of teaching effectiveness (Wachtel 1998). Those reports are very important as they tell academics how the students feel about the course. Moreover, the SET and SEC reports are considered to provide: valid, reliable, and worthwhile information (Marsh and Roche 1997, Wachtel 1998). Therefore there was a need to investigate this issue. The results from those reports revealed that students from second year were significantly more positive in their preferences towards the course than third year students. Constructive alignment theory, first described by Biggs can explain these significant shifts in student attitude to the course between the two cohorts (Biggs 1996). In this theory, Biggs advocates the alignment between the four main components of any course, namely: course objectives, the content, the assessment tasks and the expected learning outcomes (Biggs 1996). Aligning these elements will ensure compatibility and consistency between the 'curriculum' (whatever shape that takes), the teaching method and the assessment set (Biggs and Tang 2007, Walsh 2007). This theory is also applicable in structural components of the degree, in that the degree should be vertically and horizontally aligned to increase student engagement with the content (Biggs 1996). It is also essential that any course should be planned in relation to the overall degree undertaken by the student, with course content aligned with degree objectives to help students' engagement and connection with their courses. Research confirms that while many students can memorize a vast amount of information, they might not be able to reproduce it in a real life situation (Ramsden 2003). It has been suggested that the main reason for this discrepancy is that students are not able form connections between the information they learned in each course of their degree, instead handling each course as a separate unit (Ramsden 2003). Therefore, ensuring that each course is aligned to both the other courses in a semester (known as horizontal alignment), and to the degree as a whole (known as vertical alignment), and making the students aware of this, will engage them more (Biggs and Tang 2007). 
This unity helps in producing graduates who are able to think for themselves, to respond to the changing circumstances, to be life-long learners able to integrate theory into real world cases (Ramsden 2003). Producing graduates at that level is the ultimate aim of every successful education institute and teacher. Students from the $3^{\text {rd }}$ year cohort might have felt that pharmaceutical analysis course was out of place as the main focus in this year to give them the professional training in terms of placement and clinical case studies (Davey, Grant et al. 2013). On the contrary, students from the $2^{\text {nd }}$ year might have felt that this course complement the chemistry concepts that they covered in their first year of study and the second year courses that directly link to the need for drugs to be analysed in various matrices. Tables $3 \& 4$ further support this finding. Second year students have been consistently satisfied with the course and the teaching team since its movement to the second year curriculum. It is important to note that the same teaching team has been involved in delivering the pharmaceutical analysis course since 2011 until 2015. Therefore, the pharmaceutical analysis course is better aligned with other courses in the second year curriculum. This was evident by the positive attitude from the $2^{\text {nd }}$ year students in this study. Limitations to this study include not being able to access other SET and SEC reports for other courses to check for any potential cohort effect, the small sample size, potential for non-respondent bias and self-reporting bias.

\section{CONCLUSION}

Pharmacy students are generally positive about laboratory-based courses but these tend to be run in the early part of the program with experiential placements preferred by students in the later stages of the program. The pharmaceutical analysis course is better situated within second year curriculum as it horizontally aligns with other chemistry and laboratory-based courses.

\section{REFERENCES}

[1] Albon, S. P., D. A. Cancilla and H. Hubball (2006). "Using Remote Access to Scientific Instrumentation to Create Authentic Learning Activities in Pharmaceutical Analysis." American Journal of Pharmaceutical Education 70(5): 121.

[2] Albon, S. P. and H. Hubball (2004). "A learning-centered course in pharmaceutical analysis." Am J Pharm Educ 68(5): 114.

[3] APC. (2002). "The Australian Pharmacy Council." Retrieved December 2015, 2015, from https://www.pharmacycouncil.org.au.

[4] Biggs, J. (1996). "Enhancing Teaching through Constructive Alignment." Higher Education 32(3): 347-364.

[5] Biggs, J. (2001). "The reflective institution: Assuring and enhancing the quality of teaching and learning." Higher education 41(3): 221-238.

[6] Biggs, J. and C. Tang (2007). "Teaching for quality learning at university (Society for research into higher education)."

[7] Biggs, J. B. (2011). Teaching for quality learning at university: What the student does, McGrawHill Education (UK).

[8] Davey, A. K., G. D. Grant and S. Anoopkumar-Dukie (2013). "Academic Performance and Personal Experience of Local, International, and Collaborative Exchange Students Enrolled in an Australian Pharmacy Program." American journal of pharmaceutical education 77(7).

[9] Elliot, A. J. and M. A. Church (1997). "A hierarchical model of approach and avoidance achievement motivation." Journal of personality and social psychology 72(1): 218.

[10] Marsh, H. W. and L. A. Roche (1997). "Making students' evaluations of teaching effectiveness effective: The critical issues of validity, bias, and utility." American Psychologist 52(11): 11871197.

[11] Ramsden, P. (2003). Learning to teach in higher education, Routledge.

[12] Scouller, K. (1998). "The influence of assessment method on students' learning approaches: Multiple choice question examination versus assignment essay." Higher Education 35(4): 453472. 
[13] Smith, L. L. (2007). "Pharmacy students' approaches to learning in an Australian university." American journal of pharmaceutical education 71(6): 120.

[14] Sonnert, G. and M. F. Fox (2012). "Women, men, and academic performance in science and engineering: the gender difference in undergraduate grade point averages." The Journal of Higher Education 83(1): 73-101.

[15] Trigwell, K. and M. Prosser (1991). "Improving the quality of student learning: the influence of learning context and student approaches to learning on learning outcomes." Higher education 22(3): 251-266.

[16] Wachtel, H. K. (1998). "Student Evaluation of College Teaching Effectiveness: a brief review." Assessment \& Evaluation in Higher Education 23(2): 191-212.

[17] Walsh, A. (2007). "An exploration of Biggs' constructive alignment in the context of work-based learning." Assessment \& Evaluation in Higher Education 32(1): 79-87.

[18] Willey, T., S. Edwards and V. Gondhalekar (2011). "Predictors of performance in an online financial management simulation." Journal of Business Case Studies (JBCS) 4(6): 35-42. 